\section{Capital simbólico do trabalho das visitadoras sanitárias da Fundação Serviço de Saúde Pública, Alagoas/Brasil}

\section{Symbolic capital of the work of the female health visitors of the Public Health Service Foundation in the State of Alagoas, Brazil}

Silvia Alves dos Santos

Enfermeira residente, Hospital Universitário Professor Alberto Antunes (Hupaa)/Universidade Federal de Alagoas (Ufal).

silviaphaiffer@hotmail.com

Regina Maria dos Santos

Professora, Programa de Pós-graduação em Enfermagem (PPGENF/Ufal); superintendente, Hupaa/Ufal.

relpesantos@gmail.com

Laís de Miranda Crispim Costa

Professora, Escola de Enfermagem e Farmácia e do PPGENF/Ufal.

lais.costa@esenfar.ufal.br

Amanda Cavalcante de Macedo

Diretora, Centro de Desenvolvimento de Práticas Profissionais/ Associação Brasileira de Enfermagem seção Alagoas.

amandacmacedo@hotmail.com

\section{Larissa Melo Coêlho Barros}

Enfermeira, Instituição de Longa Permanência para Idosos Lar São Francisco de Assis.

larissinha_barros@hotmail.com

Recebido em 20 mar. 2017.

Aprovado em 7 fev. 2018.

http://dx.doi.org/10.1590/S0104-59702018000400012
SANTOS, Silvia Alves dos et al. Capital simbólico do trabalho das visitadoras sanitárias da Fundação Serviço de Saúde Pública, Alagoas/Brasil. História, Ciências, Saúde - Manguinhos, Rio de Janeiro, v.25, n.3, jul.-set. 2018, p.817-839.

Resumo

De caráter histórico, o estudo analisa o trabalho das visitadoras sanitárias da Fundação Serviço de Saúde Pública, em Alagoas, entre 1960 e 1990 e o capital simbólico a elas conferido. Foram utilizadas fontes documentais e orais, estas produzidas em entrevistas realizadas com recurso da história oral temática, concedidas por visitadoras, médico e enfermeira. As informações foram analisadas com base nos conceitos de habitus, campo, capital simbólico e distinção, de Pierre Bourdieu, e revelaram que as visitadoras sanitárias foram relevantes na assistência à saúde das comunidades onde atuaram, detendo marcas distintivas para inculcar práticas sanitárias por meio de visitas domiciliares e discurso autorizado para reconfigurar o habitus higiênico das famílias. Essa atuação lhes conferiu poder e capital simbólicos legitimados pela comunidade.

Palavras-chave: história da enfermagem; políticas públicas de saúde; visitadoras de saúde; capital social.

\section{Abstract}

This study of a historical nature analyzes the work of health visitors of the Public Health Service Foundation in Alagoas between 1960 and 1990 and the symbolic capital attributed to them. Documental and oral sources were used, the latter produced in interviews conducted using thematic oral history, given by the visitors, the physician and nurse. The information was analyzed based on the concepts of habitus, field, symbolic capital and distinction of Pierre Bourdieu, and revealed that health visitors were relevant in the healthcare of the communities where they worked with distinctive approaches to inculcate health practices through home visits and authority to reconfigure the hygienic habitus of families. This activity gave them symbolic power and capital legitimized by the community.

Keywords: history of nursing; public policies in health; health visitors; symbolic capital. 
E ste estudo, de caráter histórico, tem como objeto o capital simbólico conferido pela comunidade ao trabalho desenvolvido pelas visitadoras sanitárias da Fundação Serviços de Saúde Pública (FSESP) em Alagoas. A pesquisa é vinculada ao Grupo de Estudos Dona Isabel Macintyre (Gedim), registrado no Conselho Nacional de Desenvolvimento Científico e Tecnológico (CNPq), na linha de pesquisa História da Enfermagem Brasileira e Alagoana.

Sabe-se que a FSESP foi um importante órgão no desenvolvimento de ações de educação sanitária e de saneamento básico que visava ao combate das doenças endêmicas transmissíveis que assolavam muitos estados brasileiros. A fundação é originária do antigo Serviço Especial de Saúde Pública (Sesp), criado no bojo das finalidades do Instituto para Assuntos Interamericanos (Iaia), desdobramento do acordo firmado entre o Brasil e os EUA em 1942, como parte das negociações que levaram o Brasil a atuar na Segunda Grande Guerra (Araújo, 2014; Costa, 2012; Oliveira, Barreira, 2000).

Em 1960, o Sesp foi transformado em Fundação Serviço Especial de Saúde Pública pela lei n.3.750, de 11 de abril de 1960, devido ao término do acordo entre o Brasil e os EUA, finalizando o pouco que ainda existia de financiamento e do suporte das equipes estadunidenses (Araújo, 2014; Bastos, 1996). Assim, para manter em funcionamento os programas e ações importantes por ele implementados, o governo brasileiro passou a assumir os custos da FSESP (Macedo, 2013; Quaresma, 2012).

Logo nos primeiros anos de sua implantação, o Sesp criou a Divisão de Educação Sanitária, que era responsável tanto pelo treinamento de educadores em saúde quanto pelas ações desenvolvidas nas habitações, espaços comuns, associações e escolas na região Norte e em parte do Nordeste do país (Renovato, Bagnato, 2008; Teixeira, 2008). Nessa conjuntura, as visitadoras sanitárias assumiram um papel de destaque por seu contato direto e permanente com as respectivas comunidades nas quais desenvolviam suas atividades. Depois de 1960, instituída a FSESP, o padrão de trabalho e de treinamento de visitadoras sanitárias continuou ainda por muito tempo, com algumas modificações, haja vista a necessidade de o país dar continuidade à cobertura de assistência à saúde pública, como se falava à época.

A FSESP se expandiu para outros estados brasileiros, dentre os quais Alagoas e Bahia (Silva, Ferreira, 2011; Bastos, 1996). O estudo de Costa (2012) apresenta depoimentos de enfermeiras que mencionam as visitadoras sanitárias da FSESP. Já o estudo de Macedo (2013) comenta a existência das ações desenvolvidas pela FSESP nos municípios de Pão de Açúcar e Penedo.

Esses estudos relatam a importância das ações de saúde pública desenvolvidas por essa instituição, ao encargo especialmente das visitadoras sanitárias, porém não analisam se esse trabalho se configurava como capital simbólico no campo da saúde. Contribuindo para uma nova perspectiva de exame dessa questão, estabeleceu-se como objetivo da presente pesquisa analisar o poder simbólico, na forma de prestígio e distinção social, que o trabalho de visitadora sanitária conferiu a essas mulheres nos municípios onde atuaram entre as décadas de 1960 e 1990. 


\section{Fontes utilizadas na pesquisa}

Trata-se de uma pesquisa de cunho histórico que abrangeu o período de 1960 a 1990, período de funcionamento da FSESP no Brasil, sendo o seu marco inicial a promulgação da lei n.3.750, de 11 de abril de 1960, e o marco final a publicação da medida provisória n.151, de 15 de março de 1990, que incorporou a FSESP à Fundação Nacional de Saúde (Funasa) (Brasil, 2004), já após a promulgação da Constituição Brasileira de 1988, que instituiu o Sistema Único de Saúde (SUS).

Na pesquisa histórica prevê-se a composição de um corpus documental que reúne as fontes que subsidiarão o estudo, entendendo-se fonte histórica como o instrumento que o historiador examina e analisa, podendo ser vista como testemunha de uma época ou de um discurso (Barros, 2013, 2012). Nesse caso, as fontes foram documentos encontrados em uma antiga unidade da FSESP no povoado de Sinimbu, na cidade de Delmiro Gouveia, no alto sertão alagoano. Na sede da Funasa, em Maceió, nada foi encontrado, embora a FSESP tenha sido incorporada a essa fundação após o advento do SUS.

Essa situação não surpreende, pois não é raro documentos importantes serem desprezados sem os devidos cuidados nem as leis serem cumpridas no que diz respeito ao processo de tratar, arquivar e se desfazer de documentos, perdendo-se informações preciosas para a análise dos fenômenos sociais vividos (Mendes, 2012). O corpus documental também foi composto pelos depoimentos de 11 visitadoras, uma enfermeira e um médico, sendo que três delas (visitadoras Nancir, Daluz, Valéria) atuaram na cidade de Pão de Açúcar; uma (visitadora Janicleide), no povoado Sinimbu, em Delmiro Gouveia; cinco (visitadoras Janilda, Eliane, Jucélia, Graça e Edileuza), no povoado de Ponta Mofina, no município de Penedo; uma (visitadora Marilene), no município de Piaçabuçu, que na época era grafado "Piaçabussu" e também pertencia ao município de Penedo; e a última (visitadora Margarete), na cidade de Coruripe. O médico e a enfermeira foram encontrados na capital alagoana, Maceió.

Após concordância e assinatura do termo de consentimento livre e esclarecido e do termo de cessão do depoimento para uso nesta e em pesquisas futuras, as entrevistas foram realizadas com recursos metodológicos da história oral temática e o apoio de um roteiro semiestruturado. A perspectiva era acrescentar aos documentos vozes capazes de esclarecer fatos ainda não estudados. As entrevistas foram gravadas em dispositivo tipo MP3. Logo em seguida, foram transformadas em documentos escritos pela transcrição na íntegra com edição apenas de vícios de linguagem que dificultassem a compreensão do texto.

As informações foram analisadas quanto ao valor de prova do acontecimento estudado, estabelecendo-se a confrontação entre a nova narrativa, a literatura publicada e os conceitos de habitus, campo, capital simbólico e distinção, de Pierre Bourdieu, extraindo-se uma história social resultante dessa triangulação.

Este estudo atende às normas que regem as pesquisas com seres humanos e respeita os princípios éticos de acordo com a resolução n.466, de 12 de dezembro de 2012, do Ministério da Saúde (Brasil, 2012). No que coube, observou também a resolução n.512/2016, considerando se tratar de pesquisa histórica na área de enfermagem. Foi criteriosamente discutido com cada participante a disposição em deixar-se identificar pelo seu nome, haja 
vista cada um ocupar um espaço social que lhe confere autoridade para dizer o que diz, porquanto sujeito da história vivida. Todos concordaram em ser chamados pelos seus próprios nomes com orgulho. O projeto da pesquisa foi submetido ao Comitê de Ética da Universidade Federal de Alagoas (Ufal) via Plataforma Brasil, sendo aprovado conforme o parecer consubstanciado n.53795916.5.0000.5013.

\section{A formação das visitadoras sanitárias: o habitus profissional desejado}

A fim de compreender como o trabalho foi desempenhado pelas visitadoras sanitárias da FSESP em Alagoas e sua inserção na comunidade durante o período do estudo, fez-se necessário considerar as influências recebidas durante essa trajetória que contribuíram para formação e absorção do habitus profissional, condição necessária para desenvolver seu trabalho no campo específico dessa instituição.

A proposta de trabalho da FSESP era a de investir em educação sanitária e ação de controle das doenças infantis imunopreveníveis, acompanhamento das gestantes e dos nascidos no primeiro ano de vida, bem como o controle das doenças endêmicas como tuberculose e hanseníase. Essas ações foram feitas de tal forma que se tornaram modelos nas atividades básicas de saúde pública, numa conjuntura de alarmantes indicadores de saúde e fortalecimento do modelo de saúde hospitalocêntrico que vinha sendo implementado desde a década de 1950. Fora isso, destaca-se a introdução da profilaxia do câncer de útero, criação de bancos de sangue simples e o aperfeiçoamento dos indicadores de saúde, todas inovações trazidas pelo Sesp e a FSESP que foram incorporadas às formas de fazer saúde pública no país. A visitadora sanitária Jucélia afirma qual a prioridade do trabalho das visitadoras: "Quando nós fizemos o curso, a prioridade era crianças e gestantes, depois apareceram também os [casos] de hanseníase e tuberculose como nosso alvo" (Santos, 14 jun. 2016).

Para desenvolver esse trabalho, a FSESP recrutava, por meio de um processo seletivo, candidatas, nas suas respectivas localidades, para o curso de formação das visitadoras sanitárias, realizado em municípios onde havia escritórios da fundação, com duração de seis meses e dividido em duas partes, uma teórica e outra prática. Durante esse período, elas ficavam em regime de internato no local onde era promovido o curso, recebendo um pequeno auxílio financeiro para sua manutenção. Nesse curso as selecionadas recebiam os ensinamentos que deveriam ser incorporados pelas visitadoras, não só como conhecimentos, mas também configurados em hábitos, condutas e aparência, personificando, assim, o espírito sanitarista (Teixeira, 2008).

As visitadoras sanitárias eram escolhidas entre os moradores da região foco das ações de saúde, sendo necessário atender a um conjunto de pré-requisitos que envolviam atributos de personalidade (liderança) e hábitos de higiene. Na disputa pela vaga no curso de visitadora sanitária eram escolhidas mulheres jovens entre 16 e 28 anos, solteiras e viúvas (casadas só podiam participar com a permissão do marido). Era necessário ter o primário completo, além de atributos e habilidades pessoais e ainda responder a um questionário avaliativo com cinquenta questões, envolvendo preceitos sanitários e ordem moral. Nos anos 1960, quando se tornou fundação, a exigência de estado civil foi relaxada e o questionário foi substituído por prova. Pode-se dizer que as selecionadas detinham os elementos necessários 
à inculcação do habitus profissional desejado. Não se tem notícias de homens selecionados (Campos, 2008; Bastos, 1996).

Esses cursos beneficiavam, sobretudo, as regiões Norte e Nordeste do país, pois, pelo Programa da Amazônia, o Sesp percebeu, logo no início de suas atividades, a falta de pessoal treinado para realizar visitas nas residências da região e propagar ideias de higiene e saneamento à população. As visitadoras foram pensadas não apenas para sanar a falta de pessoal para realizar as visitas domiciliares, mas também para trabalhar aspectos de higiene dentro do seio familiar (Bonini et al., 2015).

Os primeiros cursos para visitadoras sanitárias na região Norte e no vale do rio Doce foram criados em 1943 pelo Sesp, objetivando capacitar jovens para orientar as famílias. No decorrer do tempo, com a necessidade de haver mais visitadoras, os cursos foram se expandindo para outros locais e se modificando, passando ao encargo dos órgãos regionais. Esse trabalho de formação das visitadoras sanitárias se prolongou pela década seguinte, mesmo o Sesp já tendo sido transformado em fundação, com a diferença de ter-se encerrado o sistema de internato, por ser muito dispendioso. Em 1965, com a FSESP já consolidada, modificou-se completamente o currículo do curso, passando a integrar quatro módulos com metodologias que facilitassem a aprendizagem (Campos, 2008; Teixeira, 2008).

Desde as décadas de 1940 e 1950, as visitadoras eram recrutadas em vilas e cidades de uma região, afastavam-se para a formação em outros locais e voltavam designadas para trabalhar em sua cidade ou dela próxima; posteriormente a FSESP afirmou como desaconselhável inseri-las em campos diferentes dos seus, tanto pelo custo do deslocamento de pessoal como pela não aceitação de estranhos pela comunidade (Campos, 2008).

As professoras eram predominantemente enfermeiras, com alguma ajuda do médico nas aulas teóricas e visitadoras experientes nas práticas (Teixeira, 2008), tal como dito: “A enfermeira era responsável pela formação inicial tanto de auxiliares como das visitadoras sanitárias e ainda pela formação continuada dessas profissionais" (Renovato, Bagnato, 2011, p.12), em curso de seis a oito meses de duração. Com esse intuito, foram criadas as escolas de visitadoras sanitárias em Santarém, em Itacoatiara e em Palmares. Por conta da grande demanda de visitadoras sanitárias, por parte dos estados, e dos altos custos com o treinamento de um grupo reduzido por vez, optou-se logo pela estratégia da formação em serviço (Paiva, 2015). Esse processo de formação é demonstrado nos relatos da visitadora sanitária Janilda e da enfermeira supervisora Ivete, respectivamente:

A gente foi fazer um estágio de período de seis meses na cidade em Estância! Ficava lá, trabalhava, estudava, o dia todo! Era teoria e prática. Prática era no hospital e no campo, e [teoria] na sala de estudos. Então, recebia uma bolsa de estudos para as despesas (Silva, 14 jun. 2016).

As visitadoras sanitárias eram meninas que eram recrutadas da localidade. O Sesp (estende-se à FSESP) sempre teve esse cuidado, primeiro, para não afastá-las das famílias, segundo, por causa dos laços que já existiam nessa comunidade, era mais fácil de trabalharem com a comunidade. ... O Sesp preparava essas meninas, dava um curso, uma bolsa de estudos. Durante seis meses elas eram preparadas. E depois elas eram recrutadas nas localidades, em várias localidades do estado, né, Penedo, Pão de Açúcar, Delmiro ... (Pepe, 10 jun. 2016). 
O curso contemplava noções de anatomia e fisiologia, laboratório (teoria e prática), doenças sexualmente transmissíveis (DSTs), saneamento, doenças contagiosas, nutrição, ética, higiene infantil (teoria e prática), horticultura, treinamento e supervisão das práticas higiênicas das parteiras curiosas. Além da formação profissional, as alunas recebiam noções de educação doméstica, rouparia, limpeza da casa em geral (Bastos, 1996). Isso foi confirmado no relato de todas as participantes, sintetizados nas falas, respectivamente, de Jucélia e Janilda:

Do curso é tudo sobre saúde, como a gente devia se comportar, como a gente devia tratar as pessoas, o funcionamento de cada parte do corpo especificado. Estudava sobre o braço, músculo, a maneira de aplicar uma injeção, os cuidados com as puérperas, menarca, menopausa, noções sobre o que é vacina e sobre as doenças como tuberculose e hanseníase que, na época, só a Fundação Sesp que cuidava (Santos, 14 jun. 2016).

A gente estudou anatomia... essa parte da contaminação, de porta de entrada, de porta de saída das doenças, como entrava, como se pegava. A gente ia para o campo para ver como funcionava lá a vida da comunidade... para servir de base nos estudos. Ia para hospital... para campo de estágio né? E as visitas domiciliares (Silva, 14 jun. 2016).

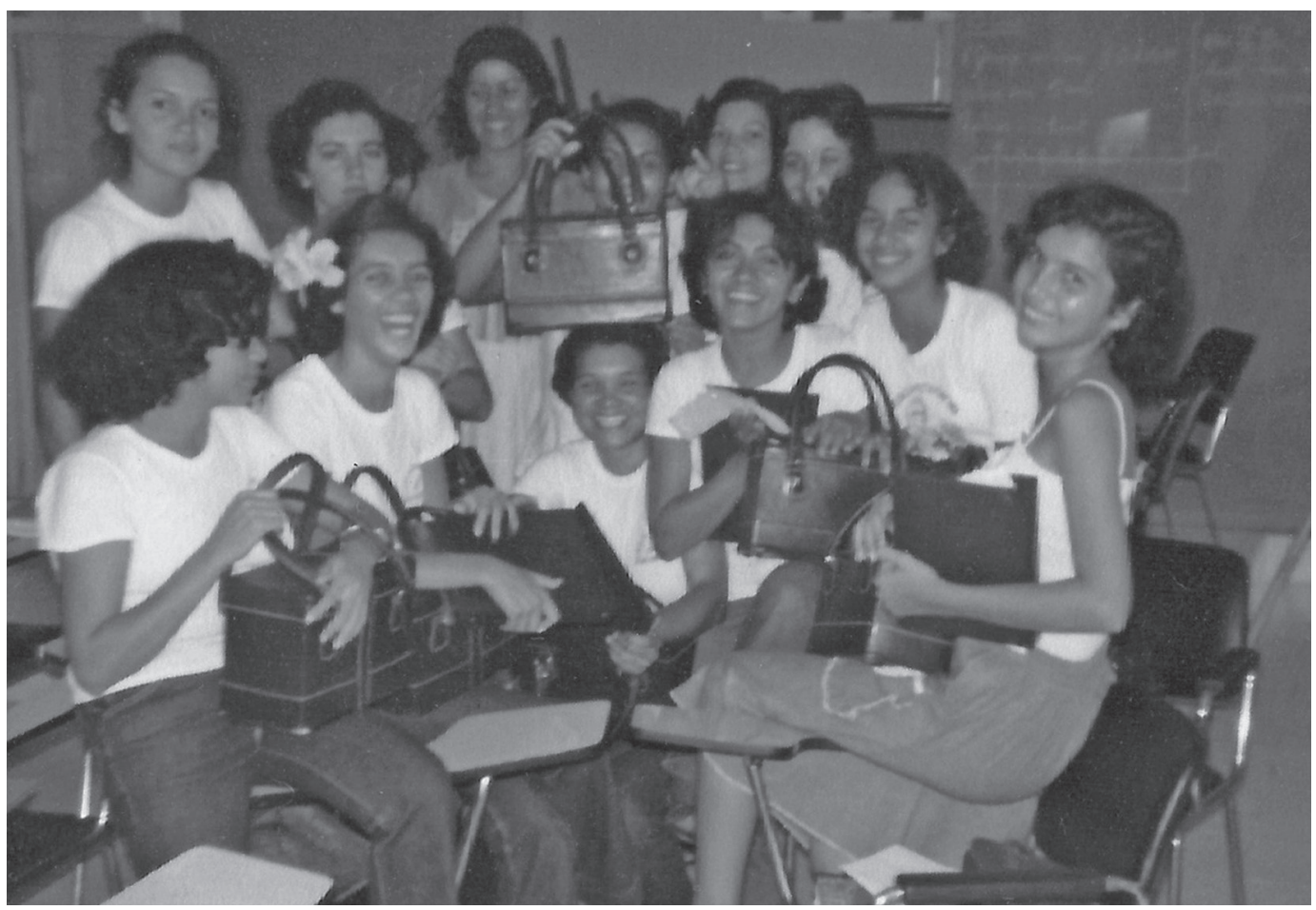

Figura 1: Visitadoras sanitárias em aula teórica na cidade de Ribeirão, PE. Algumas alunas mostram a maleta de trabalho fornecida pela FSESP (Fonte: fotografia cedida pela visitadora sanitária Edileuza ao Laboratório de Documentação e Pesquisa em História da Enfermagem/Universidade Federal de Alagoas, Ladophe/Ufal, Maceió)

A Figura 2 mostra as visitadoras sanitárias em aula prática. Observa-se que o treinamento para aplicar injeções não utilizava modelos, e as próprias alunas se prestavam para aprender uma com a outra, voluntariando-se para serem modelos reais. 


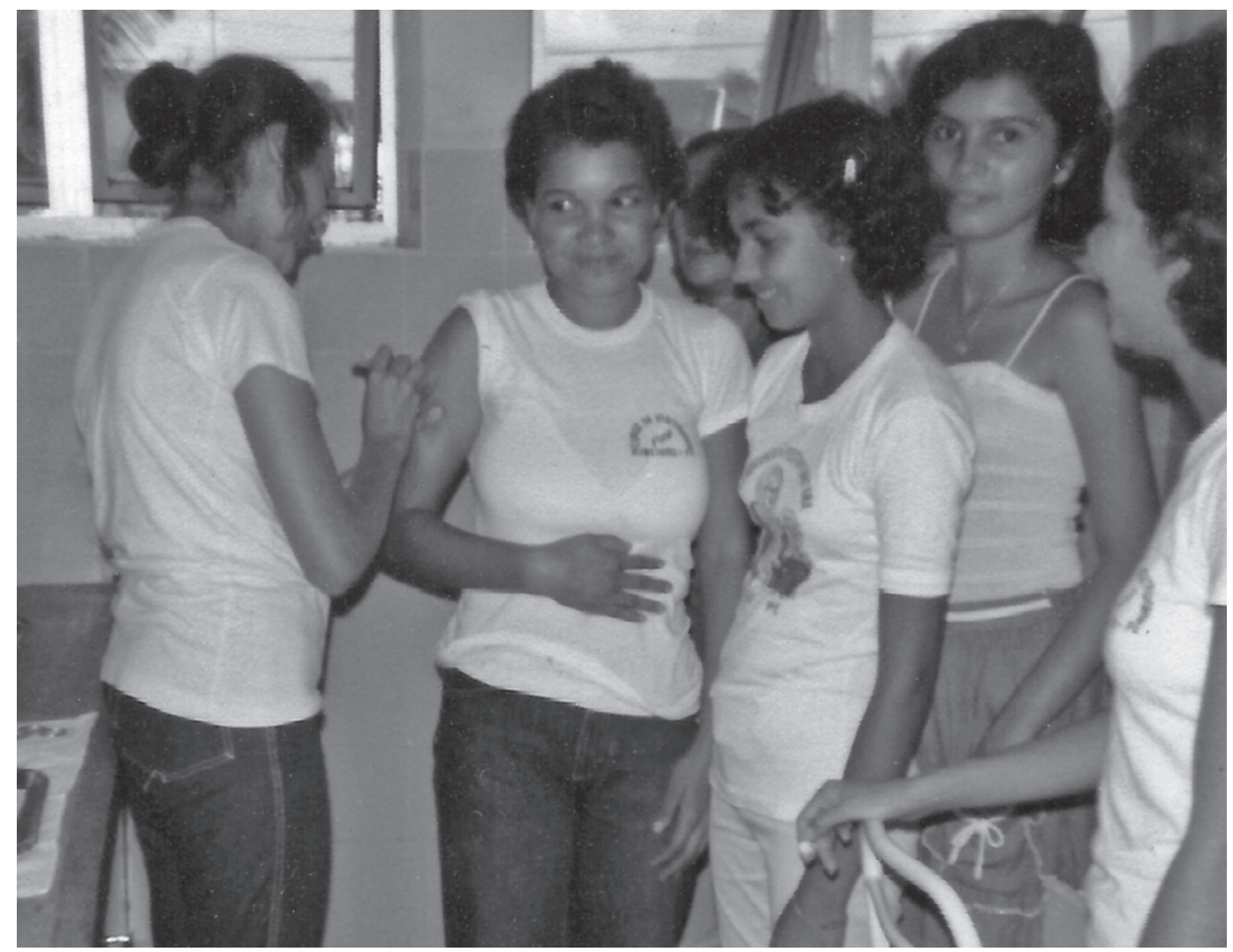

Figura 2: Visitadoras sanitárias em aula prática na cidade de Ribeirão, PE (Fonte: fotografia cedida pela visitadora sanitária Edileuza ao Ladophe/Ufal, Maceió)

Segundo Bourdieu (2011), o habitus é estruturante e estruturado. Dessa forma, o habitus profissional das visitadoras foi configurado pelo curso, que estruturou o capital científico ao submetê-las às aulas teóricas e práticas e inculcou nas candidatas o espírito sanitarista exigido pela FSESP, sendo esse um campo produtor de valores e de referências das visitadoras.

O fator que tornava o discurso das visitadoras sanitárias legítimo era o diploma de formação recebido da FSESP após a conclusão do curso. Esse diploma conferia a elas a legalidade para educar as pessoas da comunidade, ou seja, para persuadi-las a mudar suas práticas higiênicas. O diploma era, portanto, um documento importante e concreto, por meio do qual podiam ocupar o espaço no campo da saúde, uma vez que representava a objetivação do capital simbólico em capital institucional, essencial para a atuação como visitadora.

Para Bourdieu (2007), ao diploma escolar é reservado um elevado poder simbólico, transformando a escola em uma das instâncias sine qua non de manutenção da ordem social. A obtenção do diploma, por definição, "fixa" as disposições dominantes. Trata-se de uma delegação simbólica que desapossa e separa os menos competentes em favor dos mais competentes. Dessa forma, pelo curso as visitadoras incorporaram o capital institucional e profissional, e o diploma conferiu respaldo e legitimidade àquelas mulheres. Esses capitais foram considerados decisivos para que conquistassem espaço dentro do campo. 


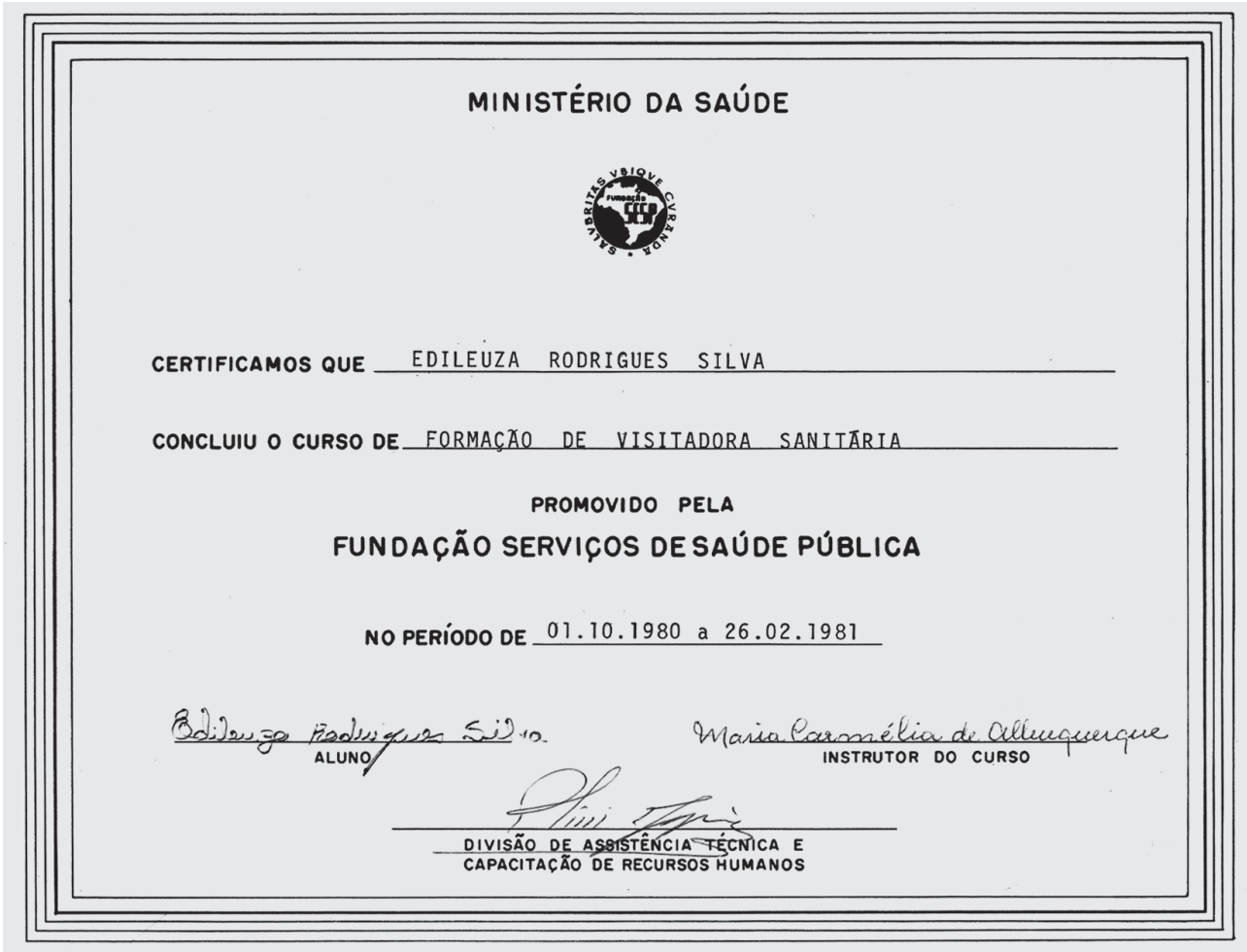

Figura 3: Diploma da visitadora sanitária da FSESP (Fonte: fotografia cedida pela visitadora sanitária Edileuza ao Ladophe/Ufal, Maceió)

Com o término do curso, as alunas deveriam ter condições de assumir as seguintes tarefas: manutenção da ordem e limpeza do posto; realização de visitas domiciliares; desenvolvimento das atividades educativas nas áreas citadas acima; encaminhamento à unidade de saúde das pessoas com sintomas de doença, contatos de casos de hanseníase e tuberculose, gestantes, infantes, escolares; além da realização de visitas regulares nas escolas para atender ao programa de saúde escolar (Bastos, 1996).

\section{O trabalho das visitadoras sanitárias e o prestígio gerador de capital social}

Na seleção e contratação de pessoal, a FSESP, ao favorecer os profissionais moradores locais, atendia a outra vantagem, pois proporcionava a fixação das pessoas no meio rural, diminuindo assim os problemas de migração. Entretanto, esse modo de selecionar foi possível somente com o pessoal auxiliar, uma vez que os profissionais de nível superior dificilmente estariam disponíveis para trabalhar em municípios rurais (Sousa, 2011).

Depois da seleção, as equipes de trabalho eram compostas conforme a complexidade da unidade, ficando as mais complexas, chamadas de "unidades mistas", por integrar assistência nas quatro clínicas básicas (médica, cirúrgica, pediatria e obstetrícia com internamento); unidades sanitárias, com profissionais de nível universitário e ocupacionais; e as simplificadas, "unidade de sanitárias (Ll)" funcionando com as visitadoras sanitárias 
e os agentes de saneamento, com visitas periódicas do médico que se responsabilizava por tudo e atendia os casos triados e marcados pela visitadora sanitária (Bastos, 1996).

No sentido de promover a saúde e prestar assistência médico-sanitária, a rede era distribuída de acordo com a população da área e com a complexidade de assistência, subdividindo-se em unidades sanitárias (L1 a L10) e unidades mistas. As L1 eram consideradas subpostos de saúde de ação restrita, situadas em localidades com menos de 2.500 habitantes, que proviam atendimento médico periódico a crianças, gestantes e adultos, desenvolviam ações no combate às doenças transmissíveis e saneamento básico. As outras unidades sanitárias ofereciam ações mais amplas, como assistência médica permanente a crianças, gestantes e adultos, controle de doenças infectocontagiosas e serviço de odontologia; já as unidades mistas englobavam as atividades de unidade sanitária e hospitalar (Bastos, 1996). Isso pode ser visto na fala da visitadora sanitária Janicleide: "A minha equipe era só eu e o Marcelino. Só nós dois. A gente tomava conta da limpeza, eu era a visitadora, era 'a chefe' da unidade, mas fazia tudo junto com ele, entendeu? Então era nós dois e o médico uma vez por semana, o dia todo" (Lima, 15 jul. 2016).

Esse modelo de funcionamento perdurou por muito tempo, mesmo já na condição de fundação. Essa fala exemplifica a mobilização dos agentes no campo, quando a visitadora mostra posição de poder ocupada no espaço social, quando da ausência do médico: "era 'a chefe' da unidade", ou seja, na estrutura de distribuição de diferentes tipos de capital, muitas vezes são forças simbólicas que vão ao encontro de um determinado poder simbólico dominante, orientam as representações desse espaço e as tomadas de posição nas lutas com a finalidade de manutenção ou modificação dele (Bourdieu, 2011). Em outras palavras, "a posição socialmente ocupada pelos agentes detentores de um poder específico em um campo particular de existência depende, antes de qualquer coisa, dos capitais objetivados nas práticas" (Alves, 2008 p.4). Por sua vez, a posição de autoridade na ausência do médico tornava as visitadoras dignas de distinção na comunidade de onde vieram e permaneciam, agora, em posição de destaque, independentemente de a responsabilidade e o poder hierárquico estarem localizados na figura do médico. Na ausência desse, ela era a autoridade!

As visitadoras selecionadas, de volta para suas respectivas localidades, onde atuariam, ao ser admitidas nas unidades de saúde, recebiam um uniforme composto de calça ou saia, blusa, sapatos e uma maleta para carregar o material necessário visando desenvolver seu trabalho. Nessa maleta havia um campo plástico grande e outro pequeno, uma balança, um frasco de nitrato de prata para credeização dos recém-nascidos, ${ }^{1}$ folhetos para as palestras, um avental, material para curativo e a Ficha 706, que era o prontuário onde tudo era registrado. Era com esse material de trabalho que realizavam ações importantes para a atenção à saúde da comunidade, como relembram, respectivamente, a enfermeira dona Ivete e a visitadora sanitária Eliane:

Então, essas meninas faziam tudo isso. Era um trabalho muito bonito, elas tinham uma maleta com tudo, quer dizer, o básico, né! Elas tinham balança, elas tinham termômetro, elas tinham material para curativo umbilical, aventais, elas tinham o mínimo, ... era a maleta da visitadora. Então ... a Fundação fez isso muito bem. Elas faziam um trabalho muito bonito e era um elemento de ligação da comunidade com o serviço, era a ponte (Pepe, 10 jun. 2016). 
Tivemos uma farda abóbora, uma blusinha solta abóbora, com a saia azul, sapatinho fechado, tivemos uma cáqui, tipo assim, uma batinha, tivemos uma verde e uma de listrinha (Vitorino, 14 jun. 2016).

O uniforme da visitadora sanitária tinha ainda a função de tornar as mesmas reconhecidas e aceitas dentro do campo ou comunidade. Conforme Teixeira (2008), os preceitos morais e higiênicos dessas funcionárias deveriam ser corporificados em hábitos, condutas e "aparência" (destaque das autoras), não somente em palavras. Para isso, as visitadoras deveriam personificar em si certo espírito do sanitarismo, como se fossem ícones (Teixeira, 2008).

Nesse sentido, o uso do uniforme era um elemento importante de distinção e identidade das corporações de profissionais em saúde (Silva, Ferreira, 2011). A visitadora sanitária Marlene afirmou que "ele deveria estar impecável" (Santos, 11 ago. 2016). A exigência de seu uso configurou como distintivo do Sesp e da FSESP. Havia a obrigatoriedade de vários outros elementos, alguns dotados de instrumental na prática do serviço prestado pela visitadora, outros contendo em si a finalidade última da expressividade de valores, que implicava a fusão entre o corpo do indivíduo e o uniforme que o vestia (Teixeira, 2008).

Dotado de valor simbólico e significado moral, o uniforme coloca sob visibilidade quem o utiliza, permitindo a sua identificação como alguém que pertence a uma instituição ou grupo e atua como objeto diferenciador daquele em relação aos demais, pois é um tipo de vestimenta para determinada categoria dos indivíduos. Então, vestir um uniforme significa envolvimento e conformação com seus padrões sociais. Assim, não se identifica a pessoa uniformizada pelo nome, mas pela instituição que representa (Peres, Barreira, 2003).

Para Teixeira (2008, p.8-9), o uniforme possui um significado mais amplo, que não apenas a identificação funcional do exterior, constituindo um artefato corporal de dupla orientação, como especifica:

Tratava-se de um artifício material e simbólico cuja finalidade era conformar (no duplo sentido da palavra: moldar e acomodar) a subjetividade dos sujeitos da ação (as visitadoras) e dos sujeitos objetos de sua ação (os familiares, em especial mães e crianças), a ser obtida por meio da produção de um continente para um conteúdo, ou seja, de uma visualidade higiênica (asséptica e femininamente adequada), num processo de mútua determinação.

Artefato que fazia parte do uniforme da visitadora sanitária, a maleta sinalizava o reconhecimento profissional pela agência sanitária ao seu trabalho (conforme pode ser visto nas Figuras 4 e 5). Artefato, pois, simbolicamente importante, o destaque conferido à maleta atribuía à visitadora um status diferenciado em relação a outras profissionais. Esse destaque, conferido pelo habitus, era incorporado no dia a dia por meio das práticas cotidianas das visitadoras sanitárias. Como revelam os relatos das visitadoras sanitárias Eliane e Margarete, respectivamente:

[Para as visitas] levávamos uma bolsa tipo assim, uma 'frasqueirinha' e, dentro, a gente levava: três quadradinhos de plástico - um maior, um médio e um menor -, levávamos também gazes esterilizadas, e tesoura esterilizada, aquele remedinho do olho e as fichas (Vitorino, 14 jun. 2016; destaque nosso). 
Na maleta colocava curativo, porque ia fazer as visitas das gestantes, tinha povidine, ... as fichas, balança para pesar a criança, lanterninha também para olhar o ouvido da criança. Medicação que não fosse um antibiótico, um xarope, a gente ... passava (Uchôa, 7 ago. 2016).

Para compreender essa condição, faz-se necessário ter em mente que o trabalho de inculcação deve durar o bastante para produzir uma formação durável, isto é, um habitus, sendo esse o resultado de ação pedagógica, podendo ser atualizado de acordo com os espaços sociais, possibilitado a partir da criação de novas condutas pelos atores sociais. A maleta era, pois, parte fundamental do uniforme, era importante devido a sua simbologia, era uma insígnia que ajudava a caracterizar a figura das visitadoras sanitárias do Sesp e da FSESP, configurando-se em sinal indicativo de sua posição. Ademais, distinguia as visitadoras das parteiras.

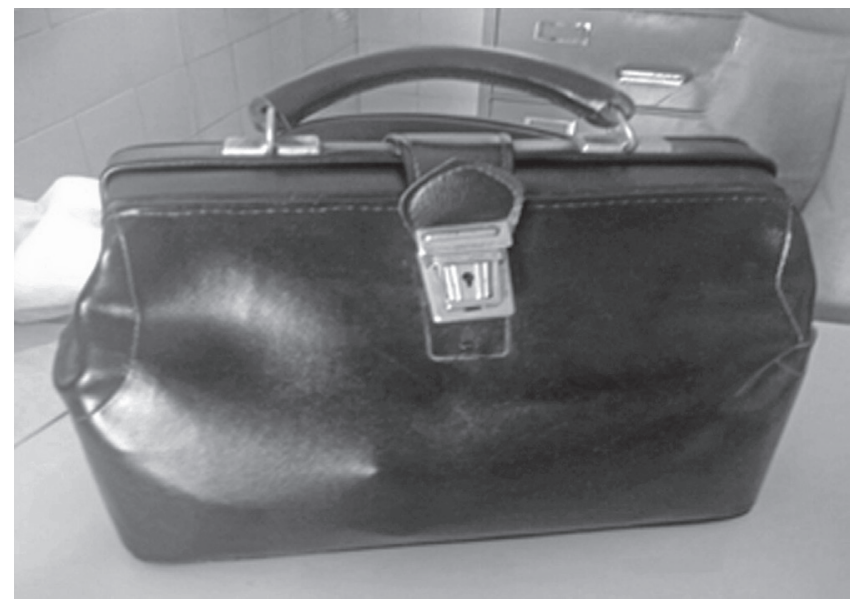

Figura 4: Imagem da maleta fechada das visitadoras sanitárias (Fonte: fotografia cedida pela visitadora sanitária Janicleide Feitosa ao Ladophe/ Ufal, Maceió)

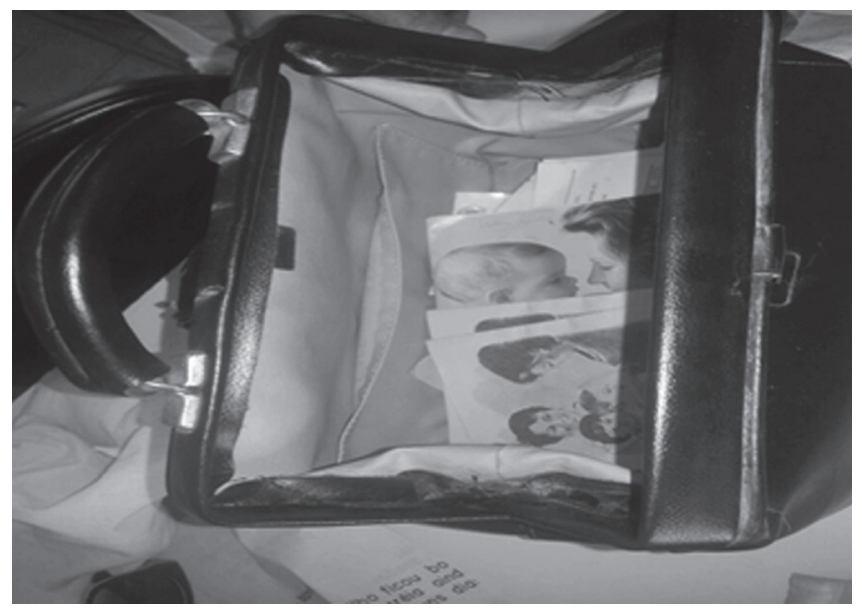

Figura 5: Imagem da maleta aberta, vendo-se parte do material que continha (Fonte: fotografia cedida pela visitadora sanitária Janicleide Feitosa ao Ladophe/Ufal, Maceió) 
Segundo Bastos (1996), a unidade básica de saúde pública era considerada um elemento social onde as famílias eram assistidas pelas visitadoras sanitárias, pelos auxiliares de saneamento e inspetores, que aproveitavam esse momento para desenvolver atividades educativas com foco nos problemas observados no domicílio ou de maior interesse para a família. Isso pode ser observado na fala das visitadoras sanitárias Daluz e Edileuza, respectivamente:

Palestras, tinha palestras com vários temas, ... a gente podia pegar um tema que estava acontecendo mais, período de diarreia a gente fazia muito palestras em cima daquele tema: diarreia (Rodrigues, 1 jul. 2016).

A gente anotava a visita. Íamos olhar toda a casa, a gente perguntava: Olhe, como é que está o banheiro, a higiene da casa? Dava uma olhada em tudo. Agora que tem um bebê é bom varrer a casa umas duas, três vezes ..., deixar as coisas limpinhas, passar um paninho pra tirar essa poeira; a criança pode pegar com a mãozinha suja e colocar na boca e daí pode ter uma diarreia (Silva, 17 jun. 2016).

À luz do pensamento de Bourdieu, foi possível compreender que o campo em que as visitadoras eram agentes possuía uma organização interna e uma escala hierárquica de profissionais. Dessa forma, a supervisão do trabalho em cada categoria revela que as relações sociais de trabalho eram verticalizadas, com as determinações partindo da sede federal para as estaduais e dessas para as unidades municipais, como explica o médico João, de uma das equipes:

A direção, nossa! ... porque a Fundação era nacional e tinha uma direção estadual, então nós, como éramos do estado, recebíamos supervisão e orientação ... da Diretoria Regional de Alagoas, os supervisores sediados na capital faziam um roteiro para o estado, então a gente recebia supervisão desse povo, sabe? Ele chegava e cobrava mesmo, vasculhava, iam para a prática, ver como é que tá aí tudo, e o que não estivesse de acordo tinha que explicar (Camurça, 25 out. 2016).

Considerando a exigência exercida em relação ao seu fazer, o estudo de Renovato e Bagnato (2011) evidencia o relevante papel das visitadoras sanitárias na comunidade. Elas eram os elementos educacionais da unidade sanitária, estando incumbidas de realizar as visitas domiciliares rotineiras, escutar atentamente as queixas e dúvidas das famílias, cabendo-lhes a orientação e o aconselhamento dessas famílias, sob a supervisão da enfermagem. Seu papel educativo era efetivo, devido ao contato estreito com as pessoas do local, adquirindo sua confiança e amizade, para então enfrentar as mazelas, doenças das populações rurais, como ilustra a fala da visitadora sanitária Janicleide: "A gente tinha que fazer atividades educativas, essa era o primordial da saúde, porque o Sesp visava à prevenção e não à cura; o objetivo do Sesp era medicina preventiva e não a medicina curativa, então, prevenir, para gente, era o passo primordial" (Lima, 15 jul. 2016).

Segundo Campos (2006), a visita aos domicílios estabelecia-se como aspecto fundamental do trabalho das visitadoras, uma vez que, ao orientar as famílias, essas profissionais também assumiam um papel político e simbólico fundamental, visto que, nessa ocasião, uma representante do poder público adentrava o ambiente privativo das populações rurais. A visitadora sanitária Valéria estabelece a relação entre as atividades educativas e a supervisão 
direta na intimidade do lar, reconhecendo como tinha o poder de adentrar o domicílio das pessoas. Sobre esse aspecto a entrevistada coloca:

A gente sempre fazia reuniões na Unidade de Saúde e centro paroquial, reunia grupos para nossas atividades, usava ... álbum seriado, criava material educativo pra tá usando nessas palestras. E o trabalho da gente era muito assim, de casa em casa, não é? Porque a gente tinha essa facilidade de visitar, de adentrar na casa das pessoas, então a gente geralmente passava as informações e orientações pra cada família, e também através de grupos (Rezende, 1 jul. 2016).

Em suas visitas, as visitadoras sanitárias tinham que observar a situação da casa e dos moradores, questionando seus hábitos alimentares e se tinham doenças. Em seguida, preenchiam uma ficha detalhando o que havia sido percebido. Além disso, competia às visitadoras assessorar as enfermeiras e médicos, sendo a visita aos domicílios atribuição primordial do seu trabalho, pois, ao orientar as famílias, estimulando maior procura dos centros de saúde, faziam conexão entre a comunidade e a FSESP (Campos, 2008). Nas visitas domiciliares, inspecionavam as casas de taipa em busca de vetores e transmissores de doenças, contribuindo muito para o controle das endemias, como relembra a visitadora sanitária Janicleide: “A população ... antigamente era muito precária, era 'pobre de marré', pobre, entendeu? Quando eu cheguei aqui, hoje não, hoje tá tudo mudado, não tem casa de taipa! Quando eu cheguei aqui era uma infinidade de casa de taipa que a gente começou a ver o barbeiro" (Lima, 15 jul. 2016; destaque nosso).

Outro profissional que trabalhava em conjunto com as visitadoras sanitárias era o auxiliar de saneamento e conservação, responsável por fazer melhorias nas condições sanitárias dos municípios e comunidades. Conforme informado, a FSESP fornecia material para a construção de banheiros, lavatórios e, por vezes, até da casa inteira, para evitar as casas de taipa, foco do barbeiro, vetor da doença de Chagas (Bastos, 1996).

O uso da instalação sanitária foi um trabalho de peso, conforme destaca a visitadora sanitária Janicleide: "A gente dava palestra pra ensinar como usar a pia, o sanitário, porque eles nunca tiveram sanitário, o costume era ir lá no mato... Pra tirar aquele costume, você tinha que fazer um monte de palestra, mostrar o que era verminose, que se morria de verminose, era um trabalho muito bem feito" (Lima, 15 jul. 2016).

Segundo Oliveira (2014), o programa de visita domiciliar foi introduzido no Brasil nas primeiras décadas do século XX, sendo sua prática realizada pelas visitadoras sanitárias, profissionais treinadas pelas enfermeiras de saúde pública e que possuíam como atribuição divulgar conceitos e noções de higiene e fornecer orientações de puericultura, pois nesse período atribuía-se a ocorrência de doenças à falta de educação sanitária.

Para Bastos, o Sesp/FSESP considerava prioritária a assistência ao grupo materno-infantil, que representava 70,98\% da população do país, com elevada taxa de natalidade e coeficiente de mortalidade infantil correspondendo, em média, a 95 óbitos por mil nascidos vivos, sendo a faixa etária de 0 a 4 anos de vida a de maior representatividade. A maioria dos óbitos infantis poderia ser evitada com vacinação, medidas médicas e educação sanitária (Jodas, 2011). Essa informação pode ser evidenciada nos relatos da visitadora Janicleide e do médico João, respectivamente: 
Quando eu cheguei aqui, vi tanta criança se perder [morrer], que botei na cabeça que no meu trabalho eu não ia deixar uma criança se perder, porque tinha mortalidade infantil aqui; era muito alta e uma das minhas metas era acabar, porque a meta deles [da FSESP] era erradicar; não era brincadeira não, a meta da gente era poderosa, era um trabalho muito bom, porque você via resultado (Lima, 15 jul. 2016).

No trabalho nós tínhamos que desenvolver programas com enfoque na saúde pública. A prioridade era logicamente para atenção materno-infantil, [criança] de 0 até 5 anos incompletos, os outros também eram atendidos, adultos porque [éramos] voltados um pouco para as crianças e para o pré-natal. O pré-natal você tinha consultas médicas, e as consultas de enfermagem, na unidade que não tinha enfermeira, eram realizadas pelas visitadoras sanitárias (Camurça, 25 out. 2016).

Conforme os depoimentos recortados, as visitadoras sanitárias faziam o acompanhamento das gestantes no pré-natal nas unidades em que não havia enfermeiras. O médico fazia duas consultas de pré-natal, e elas acompanhavam, colocando todas as queixas das gestantes na "Ficha 706", como vômito, cefaleia, doenças da infância; além disso, faziam pesquisa para sífilis, exame de sangue, fezes, orientavam sobre alimentação, higiene, fases da gestação, cuidados com o coto umbilical do bebê, banho do recém-nascido, e também auscultavam os batimentos cardiofetais.

Após o parto, faziam a visita domiciliar para orientar os cuidados com o recém-nascido, colocavam o "credê" nos olhos do bebê para "evitar sífilis" até 72 horas após o parto, orientavam a levar o bebê para vacinar, faziam o curativo do coto umbilical, orientavam a amamentação. Já com a puérpera, olhavam os lóquios, orientavam a tomada de banho morno e cuidados com a higiene pessoal.

Outros programas prioritários eram o controle e o tratamento de doença de Chagas, tuberculose e hanseníase, sendo que, para as duas últimas, o paciente era acompanhado pelas visitadoras para garantir o tratamento completo. Já no combate à doença de Chagas, as visitadoras contavam com o auxiliar de saneamento, que trabalhava junto a elas detectando as condições sanitárias e de saneamento das famílias e fazendo um levantamento das casas de taipa para que a FSESP disponibilizasse material para a construção de casas de alvenaria, com banheiro, lavatórios e fossas sépticas.

Essas condições evidenciavam o nível de vida precário da população, havendo a necessidade de priorizar e impulsionar as ações de proteção do grupo materno-infantil nos programas gerais de saúde pública. Dessa forma, os médicos e as enfermeiras ficavam responsáveis pela realização das consultas de pré-natal, e as visitadoras sanitárias, pelas atividades educativas (Bastos, 1996), confirmado por elas mesmas ao descrever o que encontravam nas casas visitadas, como se pode observar nas seguintes falas, respectivamente das visitadoras sanitárias Margarete e Edileuza:

As doenças que mais apareciam aqui naquela época eram desnutrição e verminose. Sim! E tuberculose. A comunidade era muito carente [naquela época]. Porque também mudou muita coisa, [antes] era maior a dificuldade para as pessoas se consultarem, sabia? (Uchôa, 7 ago. 2016).

As casas, lá, o pessoal tinha essa mania de escarrar na parede, as paredes de barro, você chegava lá, era aquelas placas. Quando eu for fazer um trabalho, primeira coisa 
que devo fazer aqui é o levantamento do número de verminoses. ... e faziam cocô no quintal, não tinha quem passasse no quintal (Silva, 17 jun. 2016).

Inquéritos realizados inicialmente pelo Sesp (década de 1950) e posteriormente pela FSESP (década de 1960) denunciavam a existência de sérios problemas nutricionais em todas as regiões do país, principalmente no Nordeste, onde o baixo nível econômico, educacional e de saneamento do meio ambiente, bem como da saúde e das condições de vida em geral, assumia alarmantes proporções, com famílias sem condições de obter alimentos proteicos, o que gerava crescente preocupação entre as autoridades (Bastos, 1996).

Por isso, o Sesp, desde o início de seus trabalhos, instituiu lactários na maioria de suas unidades, para fornecimento da quantidade de leite necessária, total ou suplementação. Porém, devido à carência dessas comunidades e à preocupação com o combate à mortalidade infantil, o leite de soja foi adotado como suplementação alimentar, por ser um alimento capaz de fornecer as proteínas necessárias ao organismo da criança e da mãe e ainda atender às baixas condições financeiras das populações. Em 1985, foi criado o Programa de Nutrição e Saúde (PNS) pelo Instituto Nacional de Assistência Materna (Inam), e a FSESP passou a adotá-lo como complementação ao programa de assistência materno-infantil desenvolvido pelas suas unidades, passando a atender de forma prioritária gestantes, nutrizes e crianças de 6 meses e menos de 4 anos. Com o passar do tempo, em 1987, o PNS foi substituído pelo Programa de Suplementação Alimentar, que concedia uma cesta de alimentos básicos às famílias de baixa renda (Bastos, 1996), como enfatiza a visitadora sanitária Janicleide:

Eles forneciam para os desnutridos e para as nutrizes uma... cesta básica, na consulta de enfermagem, você ia olhar se a criança [es] tava nutrida ou não, quanto ela pesava ..., se ela era bem cuidada, limpa, se a mãe tinha os cuidados de higiene pessoal,você olhava o indivíduo como um todo, se ela estivesse desnutrida, ela entrava nesse programa, e se a mãe fosse nutriz ou puérpera, ela recebia leite para a amamentação, porque até o sexto mês, como hoje, era exclusivo leite materno, então ela dava uma alimentação saudável para aquela mãe para que ela pudesse produzir leite (Lima, 15 jul. 2016).

Nos serviços de higiene infantil, a presença das visitadoras era marcante. Mais tarde, as enfermeiras de saúde pública, além do trabalho de supervisão, passaram a atuar mais diretamente no campo, ficando também incumbidas de levar às mães todos os preceitos necessários à criação de seus filhos, de averiguar quaisquer condições patológicas ou anomalias orgânicas existentes nas crianças, bem como das providências relativas aos problemas de higiene em um distrito sanitário (Faria, 2006). Nessa fase, a presença e a atuação mais direta das enfermeiras parecem ter suscitado algum sentido de disputa no campo, como mostra o depoimento da visitadora sanitária Graça, quando se atribui posição mais distinta na própria equipe com a qual trabalhava:

Eu acho que eles me tinham como uma médica. Eu era um pouco de tudo. Ainda hoje me procuram para aconselhamento. A confiança deles por mim era grande demais, pelo tempo de convivência. Muitas vezes, a própria enfermeira estava presente, mas eles recorrem a mim. E eu me orgulho demais disso. Na minha comunidade, eles tinham total confiança em mim (Cardoso, 14 jun. 2016). 
Esse depoimento de Graça remete ao sentido de luta simbólica explicado por Bourdieu (2011), exemplificado pela disputa entre os agentes sociais para impor a definição de mundo social, conforme seus interesses no campo das tomadas de posições ideológicas. Nesse caso, a visitadora disputa com enfermeiras para se estabelecer no campo da saúde e, assim, melhorar sua posição, favorecer o exercício pleno de sua profissão e, pela confiança, angariar prestígio na comunidade. Dessa forma, a posição social ou o poder que se detém na sociedade não está ligado apenas ao volume de dinheiro que se acumula ou a uma situação de prestígio que se usufrui por dispor de escolaridade ou qualquer outra particularidade de destaque, mas está na articulação de sentidos que esses aspectos podem assumir em cada momento histórico. Na perspectiva bourdieusiana, o avanço do conhecimento científico é o resultado de lutas simbólicas entre posições e agentes que disputam um tipo específico de capital, como, por exemplo, o da autoridade e/ou da legitimidade científica (Macedo, 2013).

Outra função era o programa de treinamento das "curiosas" (termo utilizado para designar as mulheres da comunidade que ajudavam as parturientes, a partir dos conhecimentos culturais, mas sem formação nenhuma), que era realizado por enfermeiras e visitadoras sanitárias, que faziam demonstrações repetitivas de filmes (quanto necessário e possível), discussão em grupo e observação, até a curiosa ter certo grau de instrução. Ao final do treinamento, recebiam uma bolsa, contendo matérias para seu uso nas suas tarefas, e passavam a ser supervisionadas pelas enfermeiras ou visitadoras sanitárias (Teixeira, 2008; Bastos, 1996).

As visitadoras atuavam junto às "parteiras curiosas", procurando ganhar sua cooperação voluntária para o treinamento. O controle era feito por meio do compromisso das curiosas de voltar à unidade de saúde após cada parto para repor os materiais da bolsa que recebiam nos treinamentos. Caso não o fizessem, o uso da bolsa seria suspenso até que acontecesse um novo treinamento (Teixeira, 2008). A visitadora sanitária Nancir e o médico João, respectivamente, corroboram com essa afirmativa citando exemplos de como isso era vivenciado:

A gente monitorava as parteiras com palestra, fornecimento de material para as bolsas que elas tinham, que a fundação FSESP fornecia e ... tinha todo o material para elas trabalharem... tinha uma reunião todos os meses com elas na unidade [de saúde] para a gente ver a questão das bolsas. Na bolsa tinha um avental, luvas, tesoura para cortar o cordão umbilical, gases esterilizadas, nitrato de prata para colocar no olhinho do recémnascido, ... uma toalha de plástico, um campo para colocar o bebê, aí tem uma bolsinha que a gente mesmo fazia, só eu não, os [funcionários] da L1 porque a gente fazia todo o material ... e fornecia e a gente fazia uns 'kitizinhos' e entregava (Santos, 1 jul. 2016).

Havia uma interação muito grande onde elas [parteiras] eram fonte de informação [de] toda criança que nascia no município. Mas tinha o controle dessas parteiras que informavam que nascia criança na rua tal, e mais, íamos no hospital saber também da relação dos que nasceram pra receber a visita da visitadora (Camurça, 25 out. 2016).

Quando terminava a primeira fase do treinamento, as parteiras eram vinculadas a uma unidade de saúde e ficavam sob a supervisão contínua das enfermeiras e visitadoras. Mas isso não implicava vínculo formal entre as parteiras e o Sesp e também não existia qualquer forma de remuneração pelos serviços supervisionados prestados às parturientes (Silva, Ferreira, 2011). Assim lembra o médico João: 
Elas [as parteiras curiosas] eram cadastradas na unidade e regularmente iam à unidade para ter contato com a enfermeira e visitadora para orientações ... e pegar o material de curativo. Levavam os pacotes esterilizados, porque lá tínhamos autoclave... para esterilizar, para que elas levassem e guardassem tudo num local, para a hora que fosse proceder o parto (Camurça, 25 out. 2016).

Dessa forma, as parteiras, após serem treinadas, continuavam a atuar como praticantes de um ofício popular de cura, típico do estilo de vida das pequenas comunidades interioranas. Sob a supervisão de visitadoras sanitárias e enfermeiras de saúde pública, as parteiras treinadas recebiam periodicamente novas instruções sanitárias, com o intuito de manter as colaboradoras do Sesp atualizadas, sondando adesão delas às práticas higiênicas ensinadas durante o treinamento (Silva, Ferreira, 2011).

As visitadoras eram profissionais que realizavam ainda atividades de educação (palestras) na comunidade, utilizando para esse fim álbuns seriados, folhetos, panfletos, desenhos e fotografias sobre alimentação, doenças transmissíveis, privadas higiênicas e uma cartilha intitulada "Proteja seu filhinho contra a diarreia" (que descrevia as causas e ensinava a se prevenir da doença). Essa cartilha era distribuída durante as palestras, reuniões, assim como os outros materiais citados, ou fixada em locais específicos da comunidade. Tudo possuía uma linguagem simples, devido ao elevado índice de analfabetismo, principalmente das populações rurais (Bastos, 1996).

O trabalho das visitadoras era reconhecido pela comunidade e por elas próprias; nas palavras - respectivamente - das visitadoras sanitárias Marlene e Graça:

Ah, bom, porque eu sou 'sorrisão' em pessoa!? Então meu trabalho era, até não só para as pessoas da comunidade, mas... Eu digo com muita satisfação com muita alegria, muita simplicidade, dou graças a Deus porque foi o Divino Espírito Santo que me inspirou. E... fui reconhecida pela coordenadora como uma boa visitadora, então, pra mim, é o maior presente (Santos, 11 ago. 2016; destaque nosso).

Nosso trabalho na unidade era de um tudo... Vacina, curativo, aplicávamos injeção, cuidávamos da medicação na farmácia, fixávamos lâmina para exame de sangue; no final do mês, nas unidades do interior, prestávamos conta à enfermeira a cada trinta dias (Cardoso, 14 jun. 2016).

O trabalho das visitadoras era supervisionado pela enfermeira supervisora da sede de Maceió, que fazia visitas periódicas a todas as unidades de saúde da FSESP do estado, orientando as visitadoras se percebesse algo que não estivesse de acordo com o treinamento recebido por elas. A partir dessa supervisão, a enfermeira fazia um relatório, para enviar juntamente com as metas alcançadas pelas unidades. Se a meta não fosse cumprida, os funcionários recebiam uma advertência que vinha da sede no Rio de Janeiro, dirigida à unidade municipal e à diretoria regional de Maceió. Era um sistema organizado e verticalizado, como relata a enfermeira dona Ivete:

Eu dizia muito 'o Sesp cobra muito', o pessoal dizia assim 'a senhora cobra muito', mas eu recebia a cobrança de cima, A cobrança era vertical. Tudo tinha umas avaliações dos profissionais, se você não correspondia, você era dispensado! Então essa cobrança vinha de cima pra baixo. Você era cobrada e você cobrava, lá em baixo também, lá 
na ponta, você cobrava também! Então, eu tenho muito orgulho de ter trabalhado na Fundação! Muito orgulho! (Pepe, 10 jun. 2016).

A Figura 6 mostra a realização de palestra em visita ao município de Penedo da maior autoridade da FSESP, médica sanitarista Elisa Vianna Sá, para supervisão dos trabalhos que vinham sendo realizados e também para contato com as visitadoras:

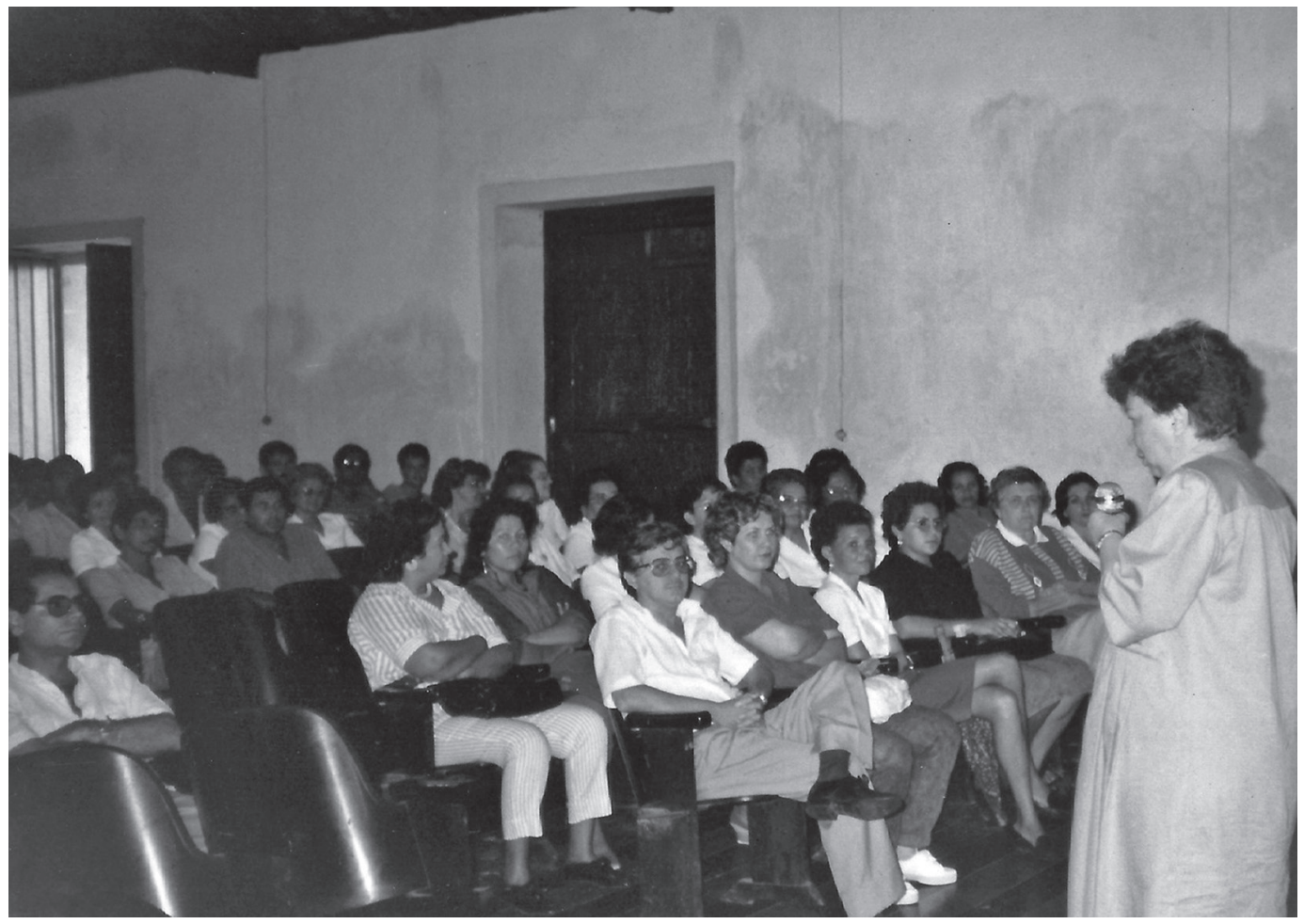

Figura 6: Visita da presidente da FSESP a Penedo (AL) (Fonte: arquivo pessoal da visitadora sanitária Edileuza, fotografia cedida ao Ladophe/Ufal, Maceió)

\section{Reconhecimento comunitário como capital simbólico das visitadoras sanitárias}

Considerando a perspectiva bourdieusiana, vê-se que o capital cultural das visitadoras era composto pelos conhecimentos reconhecidos nos certificados de treinamentos e capacitações, bem como pela habilidade adquirida na prática cotidiana, os quais auferiam respeito e prestígio nas comunidades onde atuavam. Nesse sentido, esses capitais se reconfiguraram em capital social, uma vez que se constituíram como o quantum de penetração dessas profissionais na vida cotidiana daquela comunidade, pela partilha da própria cultura. Nancir, visitadora sanitária da Unidade Mista de Pão de Açúcar, destaca o respeito e a distinção social que o cargo lhe conferia: "A gente era muito respeitada, tinha uma credibilidade! Quando a gente chegava e fazia a nossa visita, [quando] a gente se identificava e dizia que era da Fundação Sesp, nossa, a gente era super bem-recebida, tinha gente que queria dar presente!" (Santos, 1 jul. 2016). 
O depoimento da visitadora Valéria deixa muito claro o reconhecimento e a importância do trabalho das visitadoras sanitárias para a comunidade:

Na época da visitadora sanitária, era muito importante o papel dela na comunidade, o vínculo que a visitadora tinha com a comunidade era muito grande, não é? A comunidade confiava muito no trabalho da visitadora, pelo menos ... as pessoas [com] quem trabalhei, outras visitadoras sanitárias, a gente sentia isso na comunidade, que o vínculo era muito grande, e existia essa confiança muito grande no trabalho da visitadora (Rezende, 1 jul. 2016).

Por outro lado, nos municípios mais distantes e desprovidos de recursos humanos e institucionais para atender às necessidades de saúde da população, as visitadoras sanitárias representavam a única alternativa de cuidado, mormente para prevenir os agravos decorrentes das péssimas condições de vida, da pobreza. Janilda, visitadora sanitária da L1 de São José da Tapera, ressalta o quanto elas foram o único recurso profissional disponibilizado para as comunidades. Isso as tornava relevantes e socialmente indispensáveis, conferindo-lhes poder e distinção, como reconhecem: "A relação de lá [com a comunidade] era muito boa! Muito bom trabalhar no interior. A gente se sente uma pessoa bem reconhecida! Uma pessoa que passa confiabilidade. A gente ficava lá praticamente sozinha, e o médico ia uma vez por semana. Só que a gente tinha que dar assistência" (Silva, 14 jun. 2016).

Essa confiança das pessoas da comunidade refletia o capital social que essas profissionais possuíam, pois faziam com que sua fala fosse acreditada e tida como verdadeira; como aquilo que de fato deveria ser seguido e que traria o resultado esperado. A posição ocupada por elas ante a comunidade as tornava detentoras de capital social elevado e revelava a "força" que suas palavras poderiam atingir, conferindo legitimidade ao seu discurso (Bourdieu, 2011).

É válido enfatizar que o trabalho das visitadoras era muito respeitado, aceito e alcançava bons resultados, segundo os depoimentos analisados, uma vez que causara mudanças no modo de vida das pessoas, como demonstra a fala de Nancir, testemunhando o fruto de seu trabalho:

É um grande orgulho, sempre digo isso, porque é uma satisfação ajudar as pessoas; isso a gente tem de bom no nosso trabalho; é sentir que aquela pessoa está fazendo o que a gente orientou e ver aquele resultado, ver aquela satisfação [das pessoas], eu gostaria de deixar assim registrado a minha satisfação ... de ser visitadora (Santos, 1 jul. 2016).

De acordo com a teoria de Bourdieu (2011), o lugar é um espaço de distinção onde o poder se afirma e é exercido de forma tão sutil, que não é percebido como uma violência simbólica. Nesse sentido, é interessante verificar na fala das visitadoras como adentravam o espaço das famílias para ensinar preceitos de higiene, nutrição e prevenção de doenças. Campos (2006) observa que, durante a visita aos domicílios, as visitadoras sanitárias incentivavam sua clientela a abandonar as práticas de cura tradicional e a aceitar, em seu lugar, a medicina científica, ou seja, aceitar que seus costumes eram errados e o que era ensinado estava correto.

O capital social e cultural compreende as relações de poder simbólico existentes entre os profissionais de campos da saúde. Nesse sentido, os agentes ocupam espaços diferenciados e 
hierarquizados, de acordo com a posse do capital social que lhe confere posições, poderes e força, os quais asseguram a autonomia. Sob a perspectiva de Bourdieu, percebe-se que o capital cultural que as visitadoras possuíam conferia-lhes respeito e prestígio nas comunidades onde viveram e agiram.

\section{Considerações finais}

Ao explorar a memória e as lembranças das visitadoras sanitárias sobre o seu trabalho na Fundação Serviços de Saúde Pública em Alagoas, verificou-se que ele conferia a elas capital simbólico incorporado sob a forma de prestígio e distinção. Os discursos dos 13 participantes produziram fontes primárias que, juntamente com a literatura sobre o tema e o referencial teórico adotado, revelaram que o trabalho desenvolvido pelas visitadoras da FSESP era considerado de importância, visto que as ações domiciliares se tornaram uma alternativa promissora para resolver os problemas práticos que afligiam essas localidades.

Seu papel primordial consistia em uma educação sanitária que levasse informação às pessoas, com o objetivo de mudar comportamentos, costumes e práticas corporais, adequando-os a preceitos higiênicos. Em atuação conjunta com a realização das obras, educadores realizavam um trabalho de informação, conscientização e mobilização das comunidades, incentivando-as a modificar seus hábitos, tarefa diária das visitadoras. Com esse trabalho, as visitadoras conquistaram a confiança, o prestígio e a credibilidade das pessoas dessas comunidades.

A visitadora desfrutava de prestígio e distinção em virtude da posição que ocupava tanto na FSESP, após a sua formação, como na comunidade, onde desempenhava um papel de liderança, o que lhe conferia autonomia. Isso tornou as visitadoras sanitárias detentoras de um discurso autorizado sobre as práticas de educação sanitária, por meio do qual se inculcaram preceitos higiênicos com a finalidade de promover a saúde das comunidades onde elas trabalhavam. Com isso, eram bem recebidas e respeitadas, sendo reconhecidas pelas pessoas da comunidade.

A distinção atribuída às visitadoras sanitárias era reconhecida pelo uniforme que usavam durante o trabalho e pela maleta na qual portavam os equipamentos necessários às ações de saúde. Seu uso era um rito que visava confirmar na comunidade a sua identidade de profissional pertencente à FSESP, detentora do espírito sanitarista desejado, numa valorização do trabalho associado ao uniforme. Ressalta-se, pois, o valor simbólico do uniforme, que não delimita só a estética ou manifestação ornamental, mas tem seu uso carregado de significado simbólico.

Ao ocupar espaços hierarquizados, as agentes fazem uso de capital social para demonstrar suas posições a fim de garantir sua a autonomia. Assim, o diploma da visitadora sanitária se caracterizava como um distintivo dotado de poder simbólico, o que sustentou o discurso institucional autorizado, utilizado por elas na saúde e no campo social. Portanto, o capital cultural que as visitadoras possuíam provinha dos saberes e conhecimentos adquiridos e reconhecidos por meio dos diplomas e títulos fornecidos pela FSESP ao término do curso, os quais lhes conferiam respeito e prestígio dentro das comunidades onde desenvolviam seu trabalho. 
Por fim, conclui-se que o quantum de capital simbólico era equivalente à demonstração de reconhecimento das visitadoras sanitárias pela comunidade, que nelas reconhecia a sua própria cultura e, assim sendo, reconhecia como legítimos os ensinamentos que recebia e os incorporava a um habitus social reconfigurado.

\section{NOTA}

${ }^{1} \mathrm{O}$ nitrato de prata era chamado por elas de "credê", e seu nome comercial à época era Argirol.

\section{REFERÊNCIAS}

ALVES, Emiliano Rivello.

Pierre Bourdieu: a distinção de um legado de práticas e valores culturais. Sociedade e Estado, v.23, n.1, p.179-184. 2008.

ARAÚJO, Isabelle M.M.

"Saúde e desenvolvimento" no Brasil: o pensamento de Mário Magalhães da Silveira e de Josué de Castro. Dissertação (Mestrado) - Universidade Federal de Pernambuco, Recife. 2014.

BARROS, José D'Assunção.

O projeto de pesquisa em história: da escolha do tema ao quadro teórico. Petrópolis: Vozes. 2013.

BARROS, José D'Assunção.

Fontes históricas: revisitando alguns aspectos primordiais para a pesquisa histórica. Mouseion, n.12, p.129-159. 2012.

BASTOS, Nilo Chaves de Brito. Sesp/FSESP: 1942 - evolução histórica - 1991. Brasília: Fundação Nacional de Saúde. 1996.

BONINI, Bárbara Barrionuevo et al. Enfermeiras americanas do Serviço Especial de Saúde Pública e a formação de recursos humanos na enfermagem brasileira. Revista da Escola de Enfermagem da USP, v.49, n.esp.2, p.136143. 2015.

BOURDIEU, Pierre.

O poder simbólico. Rio de Janeiro: Bertrand Brasil. 2011.

BOURDIEU, Pierre.

A distinção: crítica social do julgamento. São Paulo: Edusp; Porto Alegre: Zouk. 2007.

BRASIL.

Ministério da Saúde. Conselho Nacional da Saúde. Resolução n.466. Disponível em: <http:// conselho.saude.gov.br/resolucoes/2012/reso466. pdf>. Acesso em: 10 jul. 2018. 12 dez. 2012.

BRASIL.

Ministério da Saúde. Fundação Nacional de Saúde. 100 anos de saúde pública: a visão da Funasa. Brasília: MS/Funasa. 2004.
CAMPOS, André Luiz Vieira de.

Cooperação internacional em saúde: o Serviço Especial de Saúde Pública e seu programa de enfermagem. Ciência e Saúde Coletiva, v.13, n.3, p.879-888. 2008.

CAMPOS, André Luiz Vieira de.

Políticas internacionais de saúde na era Vargas: o Serviço de Saúde Pública, 1942-1960. Rio de Janeiro: Editora Fiocruz. 2006.

CAMURÇA, João Luiz Alves.

[Depoimento]. Entrevistadoras: Silvia Alves dos Santos, Larissa Melo Coêlho Barros. Maceió: Laboratório de Documentos e Pesquisa em História da Enfermagem (Ladophe)/ Universidade Federal de Alagoas (Ufal). Gravação em MP3 (2h40min). Depoimento concedido ao Ladophe. 25 out. 2016.

CARDOSO, Maria das Graças.

[Depoimento]. Entrevistadoras: Silvia Alves dos Santos, Larissa Melo Coêlho Barros.

Maceió: Laboratório de Documentos e Pesquisa em História da Enfermagem (Ladophe)/ Universidade Federal de Alagoas (Ufal). Gravação em MP3 (1h25min). Depoimento concedido ao Ladophe. 14 jun. 2016.

COSTA, Laís de Miranda Crispim. Tessitura da identidade profissional da primeira turma do curso de graduação em enfermagem da Universidade Federal de Alagoas: contribuição do corpo docente, 1973-1977. Dissertação (Mestrado em Enfermagem) - Universidade Federal de Alagoas, Maceió. 2012.

FARIA, Lina.

Educadoras sanitárias e enfermeiras de saúde pública: identidades profissionais em construção. Cadernos Pagu, n.27, p.173-212. 2006.

JODAS, Denise Albieri et al.

Atendimento à criança e às mães: investigação do óbito evitável em menores de cinco anos. Revista Gaúcha de Enfermagem, v.32, n.4, p.669675. 2011. 
LIMA, Janicleide Feitosa.

[Depoimento]. Entrevistadora: Silvia Alves dos Santos, Maceió: Laboratório de Documentos e Pesquisa em História da Enfermagem (Ladophe)/Universidade Federal de Alagoas (Ufal). Gravação em MP3 (2h40min). Depoimento concedido ao Ladophe. 15 jul. 2016.

MACEDO, Amanda Cavalcante de. A luta das primeiras enfermeiras formadas em Alagoas por melhores posições no campo da saúde, 1977-1979. Dissertação (Mestrado em Enfermagem) - Universidade Federal de Alagoas, Maceió. 2013.

MENDES, André Oliva Teixeira.

A pesquisa histórica e o acesso à informação: dificuldades e possibilidades na era digital. In: Encontro Estadual de História, 21., 2012, Campinas. Anais... Campinas: Anpuh. p.1-17. 2012.

OLIVEIRA, Cassandra Soares de; BARREIRA, Ieda de Alencar.

A Segunda Guerra Mundial e o retorno das enfermeiras americanas ao Brasil. Escola Anna Nery Revista de Enfermagem, v.4, n.2, p.209-216. 2000.

OLIVEIRA, Stefanie Griebeler.

Melhor em casa? Um estudo sobre a atenção domiciliar. Tese (Doutorado em Enfermagem) - Universidade Federal do Rio Grande do Sul, Porto Alegre. 2014.

PAIVA, Carlos Henrique Assunção.

Izabel dos Santos e a formação dos trabalhadores da saúde. Ciência e Saúde Coletiva, v.20, n.6, p.1.785-1.793. 2015.

PEPE, Ivete Sant'Ana.

[Depoimento]. Entrevistadoras: Silvia Alves dos Santos, Larissa Melo Coêlho Barros. Maceió: Laboratório de Documentos e Pesquisa em História da Enfermagem (Ladophe)/ Universidade Federal de Alagoas (Ufal). Gravação em MP3 (55min). Depoimento concedido ao Ladophe. 10 jun. 2016.

PERES, Maria Angélica de Almeida; BARREIRA, Ieda de Alencar.

Significado dos uniformes de enfermeira nos primórdios da enfermagem moderna. Escola Anna Nery Revista de Enfermagem, v.7, n.1, p.2538. 2003.

QUARESMA, Silvia Jurema Leone. Os caminhos e descaminhos da vigilância das doenças transmissíveis no Brasil: um estudo de caso num município de Santa Catarina. Tese (Doutorado em Sociologia) - Universidade Federal de Santa Catarina, Florianópolis. 2012.
RENOVATO, Rogério Dias; BAGNATO, Maria

Helena Salgado.

Educação sanitária e o Serviço Especial de Saúde Pública (1942-1960): a doença não conhece fronteiras. História da Enfermagem: Revista Eletrônica (Here), v.2, n.2. p.105-125. 2011.

RENOVATO, Rogério Dias; BAGNATO, Maria Helena Salgado.

As contribuições do Serviço Especial de

Saúde Pública para a formação profissional da enfermagem no Brasil, 1942-1960. Revista Brasileira de Enfermagem, v.61, n.6, p.909-915. 2008.

REZENDE, Valéria Oliveira.

[Depoimento]. Entrevistadoras: Silvia Alves dos Santos, Larissa Melo Coêlho Barros. Maceió: Laboratório de Documentos e Pesquisa em História da Enfermagem (Ladophe)/ Universidade Federal de Alagoas (Ufal). Gravação em MP3 (2h40min). Depoimento concedido ao Ladophe. 1 jul. 2016.

RODRIGUES, Maria Daluz Pinto. [Depoimento]. Entrevistadoras: Silvia Alves dos Santos, Larissa Melo Coêlho Barros. Maceió: Laboratório de Documentos e Pesquisa em História da Enfermagem (Ladophe)/ Universidade Federal de Alagoas (Ufal). Gravação em MP3 (2h40min). Depoimento concedido ao Ladophe. 1 jul. 2016.

SANTOS, Jucélia Gama Feitosa.

[Depoimento]. Entrevistadoras: Silvia Alves dos Santos, Larissa Melo Coêlho Barros. Maceió: Laboratório de Documentos e Pesquisa em História da Enfermagem (Ladophe)/ Universidade Federal de Alagoas (Ufal). Gravação em MP3 (53min). Depoimento concedido ao Ladophe. 14 jun. 2016.

SANTOS, Marlene Ilário.

[Depoimento]. Entrevistadoras: Silvia Alves dos Santos, Larissa Melo Coêlho Barros.

Maceió: Laboratório de Documentos e Pesquisa em História da Enfermagem (Ladophe)/ Universidade Federal de Alagoas (Ufal). Gravação em MP3 (1h50min). Depoimento concedido ao Ladophe. 11 ago. 2016.

SANTOS, Nancir Alves Menezes.

[Depoimento]. Entrevistadoras: Silvia Alves dos Santos, Larissa Melo Coêlho Barros. Maceió: Laboratório de Documentos e Pesquisa em História da Enfermagem (Ladophe)/ Universidade Federal de Alagoas (Ufal). Gravação em MP3 (50min). Depoimento concedido ao Ladophe. 1 jul. 2016.

SILVA, Edileuza Rodrigues.

[Depoimento]. Entrevistadoras: Silvia Alves dos Santos, Larissa Melo Coêlho Barros. Maceió: Laboratório de Documentos e Pesquisa 
em História da Enfermagem (Ladophe)/ Universidade Federal de Alagoas (Ufal). Gravação em MP3 (1h43min). Depoimento concedido ao Ladophe. 17 jun. 2016.

SILVA, Maria Janilda Rocha. [Depoimento]. Entrevistadoras: Silvia Alves dos Santos, Larissa Melo Coêlho Barros. Maceió: Laboratório de Documentos e Pesquisa em História da Enfermagem (Ladophe)/ Universidade Federal de Alagoas (Ufal). Gravação em MP3 (1h20min). Depoimento concedido ao Ladophe. 14 jun. 2016.

SILVA, Tânia Maria de Almeida; FERREIRA, Luiz Otávio.

A higienização das parteiras curiosas: o Serviço Especial de Saúde Pública e a assistência materno-infantil, 1940-1960. História, Ciências, Saúde-Manguinhos, v.18, supl.1, p.95-112. 2011.

SOUSA, Amandia Braga Lima.

A Fundação Serviços de Saúde Pública (FSESP) no Amazonas: um estudo sobre sua atuação junto aos indígenas. Dissertação (Mestrado em Saúde, Sociedade e Endemias na Amazônia) Universidade Federal do Amazonas, Manaus. 2011.
TEIXEIRA, Carla Costa.

Interrompendo rotas, higienizando pessoas: técnicas sanitárias e seres humanos na ação de guardas e visitadoras sanitárias. Ciência e Saúde Coletiva, v.13, n.3, p.965-974. 2008.

UCHÔA, Maria Margareth Lima.

[Depoimento]. Entrevistadoras: Silvia Alves dos Santos, Larissa Melo Coêlho Barros. Maceió: Laboratório de Documentos e Pesquisa em História da Enfermagem (Ladophe)/ Universidade Federal de Alagoas (Ufal). Gravação em MP3 (1h33min). Depoimento concedido ao Ladophe. 7 ago. 2016.

VITORINO, Eliane Costa.

[Depoimento]. Entrevistadoras: Silvia Alves dos Santos, Larissa Melo Coêlho Barros.

Maceió: Laboratório de Documentos e Pesquisa em História da Enfermagem (Ladophe)/ Universidade Federal de Alagoas (Ufal). Gravação em MP3 (1h10 min). Depoimento concedido ao Ladophe. 14 jun. 2016. 